\title{
The outcome of postoperative radiation therapy following plastic surgical resection of recurrent ear keloid: a single institution experience
}

Reham Mohamed ${ }^{1,2^{*}} \mathbb{0}$, Abosaleh Abosaleh Elawadi ${ }^{3,4}$, Reham Al-Gendi ${ }^{3}$, Safa Al-Mohsen ${ }^{3}$, Shabeer Wani ${ }^{5}$ and Ahmed Wafa ${ }^{5}$

\begin{abstract}
Background: Ear keloids are abnormal continuously growing healing process following cutaneous injury. Surgical excision is the standard treatment strategy; however, $50-80 \%$ of cases develop recurrence. Adjuvant radiotherapy (RT) is commonly offered with a marked decrease in the recurrence rate. The variation in RT protocols used in different studies leads to a bias of results analysis. The aim is to present our experience of using surgical excision with postoperative radiotherapy for recurrent ear keloids. Also, studying different variables especially dose and keloid size that affects recurrence rate. Radiotherapy complications were reported and assessed.

Patients and methods: Keloids between 2006 and 2021 were retrospectively reviewed. Fifty-five ear keloids out of 83 cases who received RT after surgical excision were included in the study. Different dose regimens including 13 $\mathrm{Gy} / 1 \mathrm{fx}, 8 \mathrm{~Gy} / 1 \mathrm{fx}, 10 \mathrm{~Gy} / 2 \mathrm{fx}, 15 \mathrm{~Gy} / 3 \mathrm{fx}$, and other fractionated regimens were used. The Median follow-up period was 35 months. Recurrence-free rate (RFR), side effects, and prognostic factors were assessed.

Results: The overall 2-year RFR was $88 \pm 5 \%$. The 2-year RFR was $83 \pm 8 \%$ for dose regimens with biological effective dose (BED) $\leq 40$ and $92 \pm 5 \%$ for regimens with BED $>40$ Gy with an insignificant $p$ value. The 2 -year RFR was $74 \pm$ $10 \%$ compared to $97 \pm 3 \%$ for keloids $>2 \mathrm{~cm}$ and keloids $\leq 2 \mathrm{~cm}$ respectively ( $p$ value 0.02 ). The higher dose used for keloids with $>2 \mathrm{~cm}$ size significantly improved RFR. The orthovoltage therapy showed marginally better 2-year RFR compared to electron beam therapy; however, statistically insignificant ( $p$ value 0.09). The side effects were minimal with no reported second malignancy or serious G3-4 complications.

Conclusion: Excision followed by RT is a safe and effective treatment for recurrent ear keloids. Low and modest radiation doses are effective; however, a higher dose is recommended for keloids $>2 \mathrm{~cm}$. We recommend a prospective larger-scale study to test the effect of dose and keloid size on the treatment results.
\end{abstract}

Keywords: Keloid, Postoperative, Radiotherapy, Orthovoltage

${ }^{*}$ Correspondence: dr.reham71@hotmail.com

${ }^{2}$ Radiation Oncology Department, Comprehensive Cancer Center, King Fahad Medical City, Riyadh, Saudi Arabia

Full list of author information is available at the end of the article

\section{Background}

Radiotherapy for benign diseases started shortly after the $\mathrm{x}$-ray discovery in 1896 . Keloid is one of such diseases that showed decreased recurrence rate by adding postoperative radiotherapy (PORT) $[1,2]$. The continuous abnormal healing that mostly exceeds the boundary of the initial wound edges characterizes post-traumatic 
keloid formation [3]. The ear is considered the commonest site affected by keloid scarring with cosmetic complaints and infrequent pain and pruritis $[4,5]$. The proposed treatment approaches included non-invasive and invasive strategies, such as compression, intralesional injections of corticosteroids, intralesional injection of pharmaceutical agents like verapamil and bleomycin, topical therapy, laser treatment, intra-lesional cryotherapy, and surgical excision. However, it is an invasive option, resection remains the standard approach for recurrent cases following the failure of conservative measures [6-12].

Unfortunately, many studies showed that the incidence of postoperative local recurrence ranges from 50 to $80 \%$. Moreover, multiple surgical resections led to bigger recurrences in most of the clinical scenarios [13-15]. Adjuvant PORT aiming to prevent local recurrence showed its effectiveness and superiority over other options [16-18]. Radiation targets immature fibroblasts which are relatively radiosensitive compared to normal fibroblasts leading to suppression of fibroblast proliferation and hence inhibition of collagen synthesis $[15,16]$. Accordingly, radiation therapy (RT) should be considered as early as possible within 3 days following resection before fibroblast maturation $[1,13,16]$. This standard clinical practice of surgery followed by early PORT dated and proposed since 1981 by Ollestein et al. [19]. The proposed radiation dose varies in the literature with no consensus ranging from 7 Gray (Gy) to 13 Gy as a single dose or even fractionated ranging from 10 to $20 \mathrm{~Gy}$. Most studies kept the high dose per fraction ( $\mathrm{fx}$ ) as a general concept regardless of the way of fractionation being keloids have low mitotic index [20-27]. Despite its rarity, radiation-induced second malignancy is a potentially serious side effect in such benign diseases that warrants RT optimization and discussion with the patients upon offering PORT [22, 23].

\section{Aim of the study}

The study aims to present our experience of using surgical excision with PORT for the treatment of recurrent ear keloids. The variables that possibly affect treatment outcomes were studied. The possible radiation-induced side effects and complications were evaluated.

\section{Patients and methods}

The patients presented by recurrent ear keloids (Fig. 1) and treated by surgical resection and PORT from 2006 till 2021 at our hospital were retrospectively reviewed. Institutional Review Board (IRB) approval was obtained before data collection. The medical records and radiation therapy files were used to collect the following information; disease laterality, radiation dose, number of fractions, dose per fraction, radiation energy, the interval between surgery and radiotherapy, local recurrence, early and late radiation-induced side effects. Our data were compared with other data published in the literature.

\section{Surgical details}

Excision of a keloid may stimulate additional collagen synthesis, prompting quick recurrence as a possible larger keloid than the initial one. So, the strategy of limiting tissue handling is followed. All adult patients underwent surgery under local anesthesia. The common practice at our institution is complete extramarginal excision leaving 5-mm margins of healthy skin
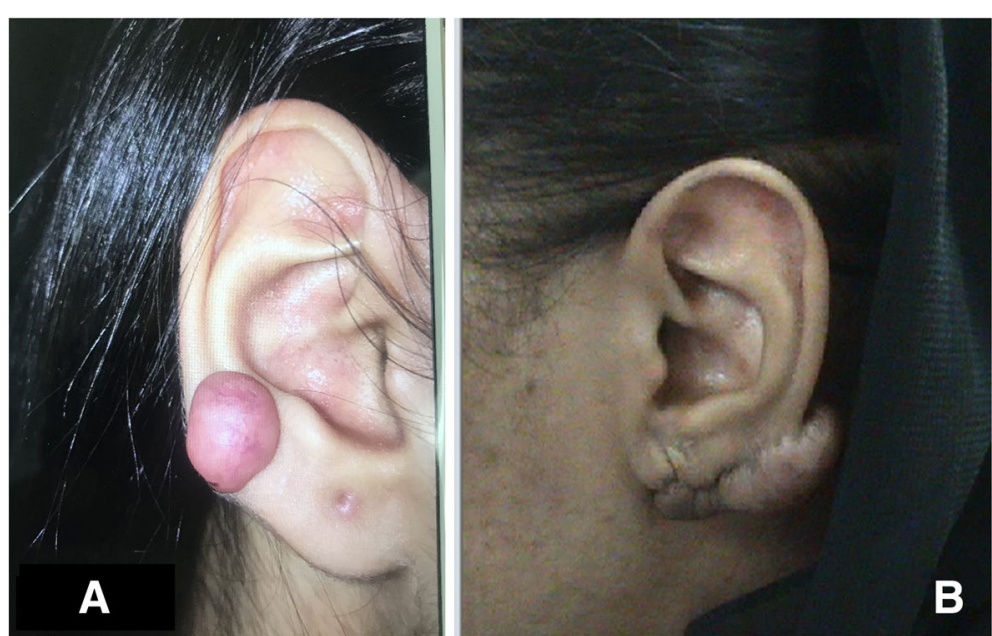

Fig. 1 Patients with recurrent ear keloids of different sizes. A Showed patient with RT ear keloid less than $2 \mathrm{~cm}$. B Showed patient with left ear keloid more than $2 \mathrm{~cm}$ 
as recommended worldwide. The incisions and wound edges are planned to be parallel to the main folding lines of the skin to decrease the recurrence rates. After undermining the surrounding skin for easy closure, the wound edges were closed under tension with absorbable subdermal and nonabsorbable subcuticular sutures.

\section{Radiotherapy details}

The radiation treatment was delivered at our department by using either electron beam therapy or orthovoltage $\mathrm{x}$-ray beam. The linear accelerator is a dual-energy HDX machine (Varian Medical System, Palo Alto, USA). The orthovoltage machine is Xstrahl 300, SN Gm0372. This machine produces 9 clinical energies of $\mathrm{x}$-ray beam from $60,80,100,120,150,180,200,250$ and 300 kilovoltage peak (kVp) with filters F1, F2, F3, F4, F5, F6, F7, F8, and F9 respectively. Patients were treated using open or closed applicators at focal spot distance $30 \mathrm{~cm}$ or 50 $\mathrm{cm}$ respectively. Open circular applicators are used with energies 60, 80, and 100 kilovolt $(\mathrm{kV})$ while closed square or rectangular applicators are used with the remaining energies of more than $100 \mathrm{kV}$.

The patients were treated in the lateral position or supine position with the head turned to the other side so that the affected ear is facing up. A suitable head-rest device is used to allow proper comfortable reproducible positioning. The target volume was determined clinically including the scar plus a 1 to $1.5 \mathrm{~cm}$ margin (Fig. 2A). The depth was chosen clinically and mostly around $0.5-1.0$ $\mathrm{cm}$. Waxed lead cutout shields were positioned around the delineated target volume to block the normal tissue. Also, a waxed lead shield is placed behind the ear to protect the neck and brain and to avoid backscatter radiation (Fig. 2B). The gantry may be rotated so that the beam exits away from the inner and middle ear if applicable. In the case of treatment by 6 mega-electron volt $(\mathrm{MeV})$ electron beam, a bolus of $0.5 \mathrm{~cm}$ thickness was applied to keep skin dose close to $100 \%$. The dose was prescribed to $85-90 \%$ isodose line. In case of treatment with higher energies of electron beam, the skin dose was calculated, and mostly bolus is not applied. In case of orthovoltage treatment, the proper energy (filter) was used as per treatment depth with the dose prescribed to $90-95 \%$ isodose line. Different fractionation schedules were used as per the treating physician.

For the sake of comparison, we used the equivalent dose in 2-Gy fractions (EQD2) of 20 Gy with biological effective dose (BED) 40 to stratify the regimens used in our department. As a benign disease, we considered the $\alpha / \beta$ ratio for ear keloid to be 2.08 similar to late reacting tissues [28]. The regimens with EQD2 $\leq 20$ Gy (BED $\leq 40)$ included $8 \mathrm{~Gy} / 1 \mathrm{fx}$ and $10 \mathrm{~Gy} / 2 \mathrm{fx}$ compared to regimens with EQD2 > 20 Gy $((\mathrm{BED}>40)$ that included 13 Gy/1fx, 15 Gy/3fx, 16 Gy/4fx, and 18 Gy/3fx.

The patients were followed up with radiation or plastic surgery departments every 3-6 months. We used telephone interviews for some patients who could not attend regular follow-up visits. Recurrence is defined as a reappearance of the keloid or progression of the residual scar elevation [16]. The recurrence-free duration is measured from the date of surgical excision till the date of local recurrence. The radiation-induced skin reactions were evaluated using Radiation Therapy Oncology Group (RTOG) grading scale [24].

\section{Statistical analysis}

Statistical package for social science version 21 (SPSS v21) was used for statistical analysis and the KaplanMeier method was used to estimate recurrence-free rate. The log-rank test was used to compare recurrence rates between groups. $P$ values of $<0.05$ were considered statistically significant. All different variables were studied and correlated with local recurrence. The student's $t$ test was used for the analysis of continuous variables. The chi-squared test and Fisher's exact test for discrete variables were used to compare proportions.

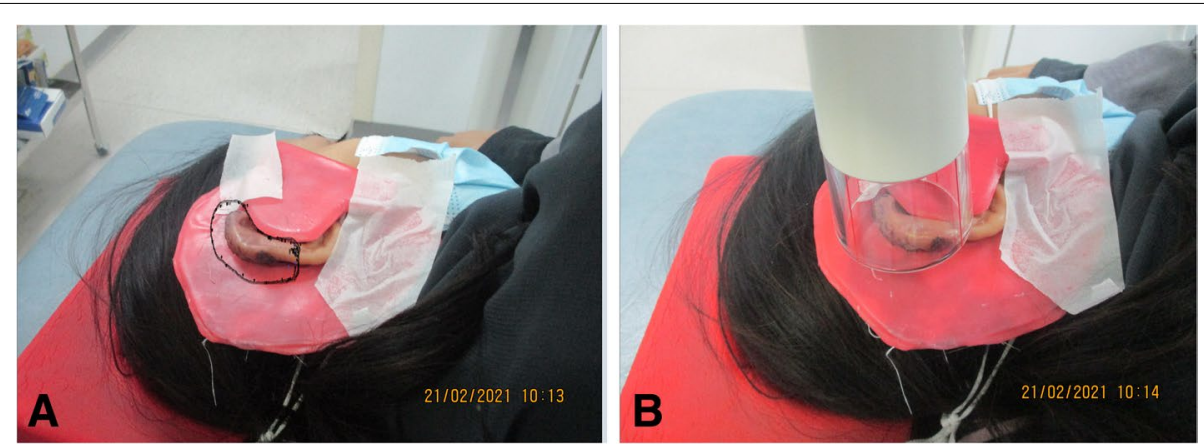

Fig. 2 Patient with Rt ear keloid treated by orthovoltage. A Showed patient with RT ear keloid with target volume determined and waxed lead shield used for normal tissue protection. B Showed the same patient with orthovoltage applicator prior to treatment 


\section{Results}

Eighty-three keloid cases registered at our radiation oncology department were screened. The cases with keloids outside the ear and hypertrophic scars were excluded and a total of 55 recurrent ear keloids were included in the study with the following characteristics shown in Table 1. Majority of patients were females (91\%) with a mean age of $24 \pm 7$ years and a range from 17 to 66 years. The main presentation was painless mass in $89 \%$ of cases. Thirty-eight (69\%) cases had a history of 2 to 3 resections before re-excision and PORT (Table 1).

The mean duration between initial presentation and PORT was $71 \pm 43$ months ranging from 19 to 180 months. The keloid size before the last surgical resection

Table 1 Patients' characteristics

\begin{tabular}{|c|c|}
\hline Variable (total no of cases; $n=55$ ) & $n(\%)$ \\
\hline \multicolumn{2}{|l|}{ Age } \\
\hline Mean age \pm SD (range) in years & $24 \pm 7(17-66)$ \\
\hline \multicolumn{2}{|l|}{ Sex } \\
\hline Female & $50(91 \%)$ \\
\hline Male & $5(9 \%)$ \\
\hline \multicolumn{2}{|l|}{ Presentation } \\
\hline Mass & 49 (89\%) \\
\hline Mass and pain & $6(11 \%)$ \\
\hline \multicolumn{2}{|c|}{ No of resections prior to definitive treatment } \\
\hline 1 resection & $10(18 \%)$ \\
\hline 2 resections & $21(38 \%)$ \\
\hline 3 resections & $17(31 \%)$ \\
\hline$>3$ resections & $7(13 \%)$ \\
\hline \multicolumn{2}{|c|}{ Duration between initial presentation and RT } \\
\hline Mean duration \pm SD (range) in months & $71 \pm 43(19-180)$ \\
\hline \multicolumn{2}{|l|}{ Referral hospital } \\
\hline Internal referral & $33(60 \%)$ \\
\hline External referral & $22(40 \%)$ \\
\hline \multicolumn{2}{|l|}{ Involved ear } \\
\hline Rt ear & $32(58 \%)$ \\
\hline Lt ear & $23(42 \%)$ \\
\hline \multicolumn{2}{|l|}{ Current clinical status } \\
\hline Free & 49 (89\%) \\
\hline Recurrent & $6(11 \%)$ \\
\hline \multicolumn{2}{|l|}{ Treatment used before RT } \\
\hline Surgery alone & $7(13 \%)$ \\
\hline Surgery and steroid injection & $48(87 \%)$ \\
\hline \multicolumn{2}{|l|}{ Size } \\
\hline $0.0-1.0 \mathrm{~cm}$ & $4(7.3 \%)$ \\
\hline$>1.0-1.5 \mathrm{~cm}$ & $20(36.4 \%)$ \\
\hline$>1.5-2.0 \mathrm{~cm}$ & $9(16.3 \%)$ \\
\hline$>2.0-4.0 \mathrm{~cm}$ & 17 (31\%) \\
\hline$>4.0 \mathrm{~cm}$ & $5(9 \%)$ \\
\hline
\end{tabular}

was $>2 \mathrm{~cm}$ in $40 \%$ of cases. Forty cases $(72.8 \%)$ received a single radiation dose either 8 Gy or 13 Gy. Two cases received $10 \mathrm{~Gy} / 2 \mathrm{fxs}, 8$ cases received $15 \mathrm{~Gy} / 3 \mathrm{fxs}, 4$ cases received $16 \mathrm{~Gy} / 4 \mathrm{fxs}$, and one patient received $18 \mathrm{~Gy} / 3 \mathrm{fxs}$. Forty-one cases out of the 55 cases received orthovoltage while $25 \%$ of the cases received electron beam therapy. The energy of $100 \mathrm{kV}$ with $3.2 \mathrm{~mm}$ aluminum half-value layer (HVL) was used for treating $64 \%$ of the cases. All of our patients received radiation within $24 \mathrm{~h}$ of surgery. The details of radiation delivered are illustrated in Table 2.

The mean follow-up period was $35 \pm 16$ months ranging from 8 to 72 months. At the time of assessment, 49 cases were free of local recurrence with 2-year recurrence-free rate (2y-RFR) $88 \pm 5 \%$. The different dose regimens used did not affect the RFR significantly with a $p$ value of 0.44 as illustrated in Table 3 and Fig. 3 .

Table 2 Radiation details

\begin{tabular}{|c|c|}
\hline Variable (total no of cases; $n=55$ ) & $n(\%)$ \\
\hline \multicolumn{2}{|l|}{ RT prescription dose } \\
\hline 8 Gy single dose & $20(36.4 \%)$ \\
\hline 13 Gy single dose & $20(36.4 \%)$ \\
\hline 10-18 Gy fractionated doses & $15(27.2 \%)$ \\
\hline \multicolumn{2}{|l|}{ Dose per fractions } \\
\hline 8 Gy & $20(36.4 \%)$ \\
\hline 13 Gy & $20(36.4 \%)$ \\
\hline 4 Gy & $4(7.3 \%)$ \\
\hline $5 \mathrm{~Gy}$ & $10(18 \%)$ \\
\hline $6 \mathrm{~Gy}$ & $1(1.9 \%)$ \\
\hline \multicolumn{2}{|l|}{ Type of RT } \\
\hline Orthovoltage & $41(75 \%)$ \\
\hline Electron beam & $14(25 \%)$ \\
\hline \multicolumn{2}{|l|}{ Orthovoltage applicator size (41 patients) } \\
\hline $3 \mathrm{~cm}$ & $5(12 \%)$ \\
\hline $4 \mathrm{~cm}$ & $20(49 \%)$ \\
\hline $5 \mathrm{~cm}$ and more & $16(39 \%)$ \\
\hline \multicolumn{2}{|l|}{ Energy } \\
\hline $100 \mathrm{kV}$ & $35(64 \%)$ \\
\hline $150 \mathrm{kV}$ & $4(7.3 \%)$ \\
\hline $180 \mathrm{kV}$ & $2(3.6 \%)$ \\
\hline $6 \mathrm{MeV}$ & $12(21.5 \%)$ \\
\hline $9 \mathrm{MeV}$ & $2(3.6 \%)$ \\
\hline \multicolumn{2}{|l|}{ Acute side effects } \\
\hline G1 & $37(67 \%)$ \\
\hline G2 & $5(9 \%)$ \\
\hline Not assessed & $13(23 \%)$ \\
\hline \multicolumn{2}{|l|}{ Late side effects } \\
\hline No late reactions & $43(78.1 \%)$ \\
\hline G1 & $8(14.6 \%)$ \\
\hline Not assessed & $4(7.3 \%)$ \\
\hline
\end{tabular}


Table 3 Recurrence free rateVariable (total no of cases; $n=55$ )

\begin{tabular}{|c|c|c|}
\hline & $2 y-R F R \pm S D$ & $P$ value \\
\hline All patients & $88 \pm 5 \%$ & \\
\hline Group received 8Gy SS & $81 \pm 10 \%$ & \\
\hline Group received 13Gy SS ${ }^{a}$ & $95 \pm 5 \%$ & \\
\hline Group received 10-18Gy Fractionated & $83 \pm 11 \%$ & 0.44 \\
\hline \multicolumn{3}{|l|}{ EQD2 } \\
\hline$\leq 20 \mathrm{~Gy}$ & $83 \pm 8 \%$ & \\
\hline$>20 \mathrm{~Gy}$ & $92 \pm 5 \%$ & 0.37 \\
\hline \multicolumn{3}{|l|}{ Size } \\
\hline Keloid $\leq 2 \mathrm{~cm}$ & $97 \pm 3 \%$ & \\
\hline Keloid $>2 \mathrm{~cm}$ & $74 \pm 10 \%$ & 0.02 \\
\hline \multicolumn{3}{|l|}{ Type of radiation } \\
\hline Orthovoltage & $92 \pm 4 \%$ & \\
\hline Electron beam & $72 \pm 14 \%$ & 0.09 \\
\hline \multicolumn{3}{|l|}{ Size and dose effect } \\
\hline \multicolumn{3}{|l|}{ Keloid $\leq 2 \mathrm{~cm}$} \\
\hline Group received 8 Gy SS & $91 \pm 9 \%$ & \\
\hline Group received 13 Gy SS & $100 \pm 0 \%$ & 0.3 \\
\hline \multicolumn{3}{|l|}{ Keloid $>2 \mathrm{~cm}$} \\
\hline Group received 8 Gy/1fx & $56 \pm 24 \%$ & \\
\hline Group received 13 Gy/1fx & $88 \pm 12 \%$ & 0.05 \\
\hline Mean follow up period in months (range) (8-72) & $35 \pm 16$ & \\
\hline $\begin{array}{l}\text { Mean time to recurrence in months (range) } \\
(5-65)\end{array}$ & $26 \pm 14$ & \\
\hline
\end{tabular}

EQD2 $>20$ Gy did not show superiority compared to EQD2 $\leq 20$ Gy. The $2 y$-RFR was $83 \pm 8 \%$ for regimens with EQD2 $\leq 20$ Gy and $92 \pm 5 \%$ for regimens $>20$ Gy with insignificant $p$ value of 0.37 . The cases that received orthovoltage showed $2 \mathrm{y}$-RFR of $92 \pm 4 \%$ compared to $72 \pm 14 \%$ for cases that received electron beam, with a borderline insignificant difference $(p$ value $=0.09$ ). The size of the keloid of $>2 \mathrm{~cm}$ at the date of the last excision showed lower $2 y$-RFR of about $74 \pm 10 \%$ compared to $97 \pm 3 \%$ in cases of keloid $\leq 2 \mathrm{~cm}$ size with $p$ value 0.02 (Fig. 4).

In a subset analysis for dose and keloid size, we targeted the keloid cases with size $\leq 2 \mathrm{~cm}$ and compared 8 Gy/1fx to $13 \mathrm{~Gy} / 1 \mathrm{fx}$ with $2 \mathrm{y}$-RFR $91 \pm 9 \%$ versus $100 \pm$ $0 \%$ ( $p$ value 0.3 ). Regarding keloid size more than $2 \mathrm{~cm}$, the cases that received a dose of $13 \mathrm{~Gy} / 1 \mathrm{fx}$ showed higher 2-year RFR ( $88 \pm 12 \%)$ compared to the cases received 8 Gy/1fx $(56 \pm 24 \%)$ with a $p$ value 0.05 as shown in Fig. 5.

Sixty-seven percent of cases developed G1 acute skin reactions and only $9 \%$ of cases developed G2 acute reactions (Fig. 6). The G1 late skin reactions were reported in $14 \%$ only of cases. There are no G2-4 late skin reactions reported as shown in Table 2. The radiation-induced second malignancy is not reported in the studied cases with a mean follow-up of 35 months.

${ }^{\mathrm{a}} \mathrm{SS}=$ single shot. Comparing patients of 8Gy SS and patients of 13Gy SS separately is insignificant also with $p$ value 0.2

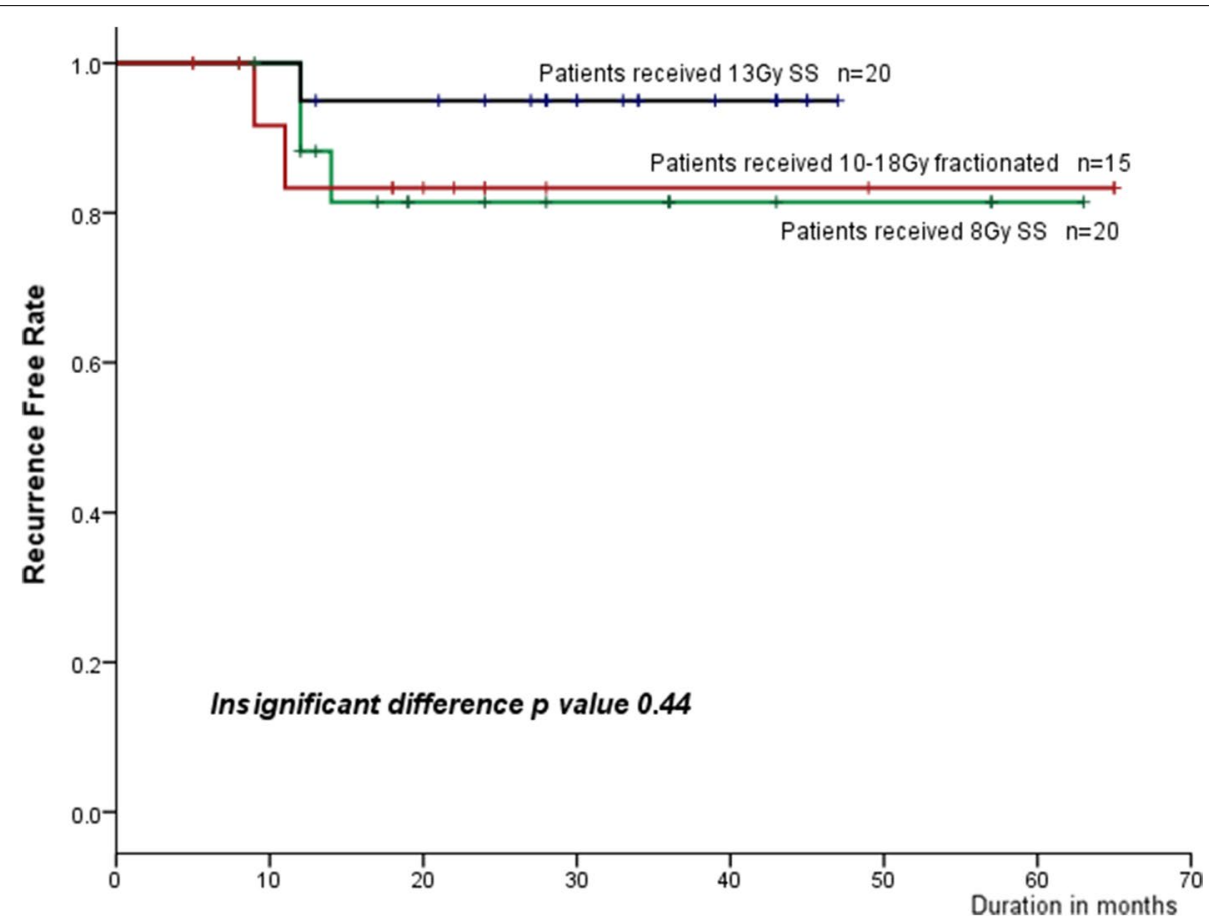

Fig. 3 The effect of different dose regimens on the recurrence rate. The curve showed insignificant difference between the used dose regimens; 13 $\mathrm{Gy} / 1 \mathrm{fx}, 8 \mathrm{~Gy} / 1 \mathrm{fx}$, and 10-18 G fractionated regimens 


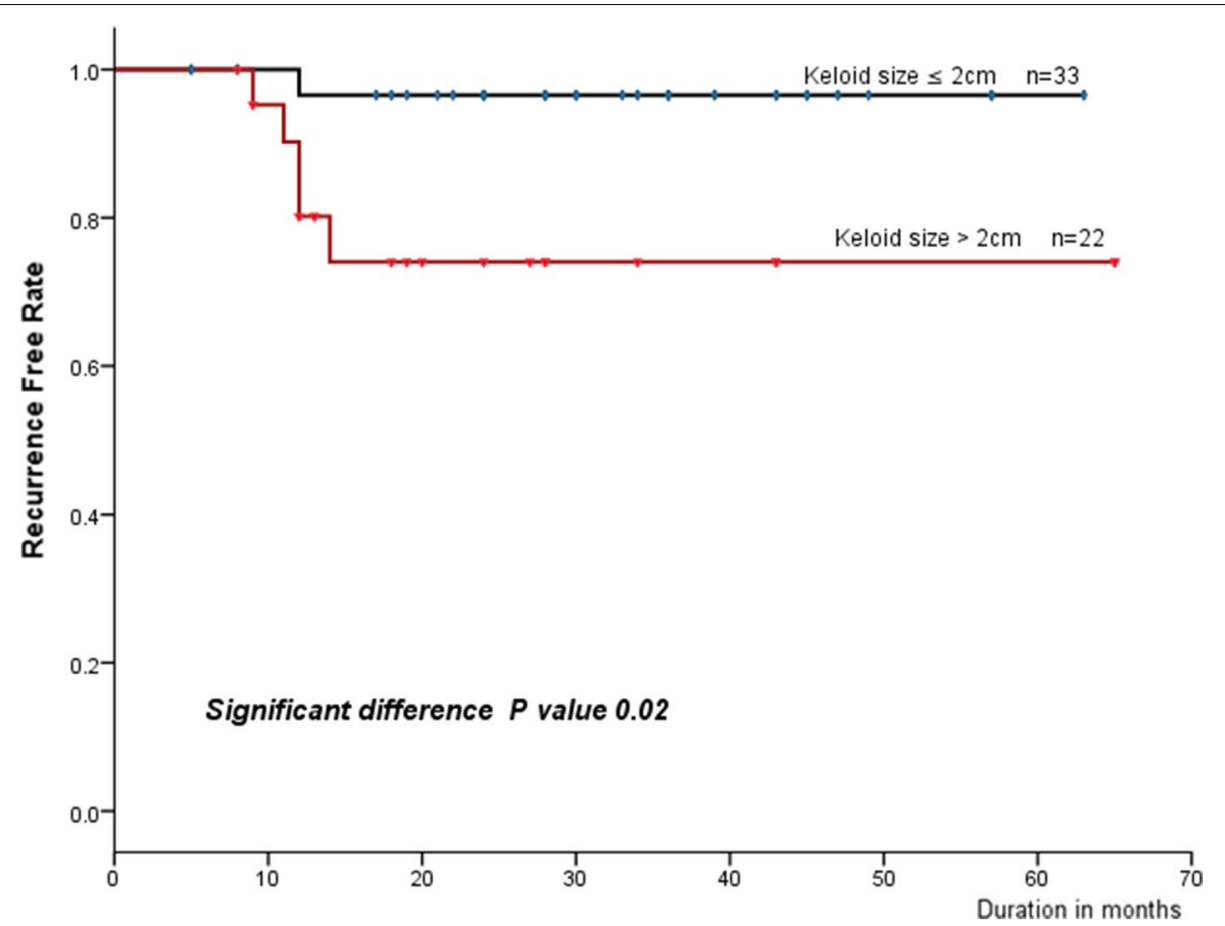

Fig 4 The effect of keloid size on the recurrence rate. The curve showed significant difference between keloid cases with size $\leq 2 \mathrm{~cm}$ and $>2 \mathrm{~cm}$

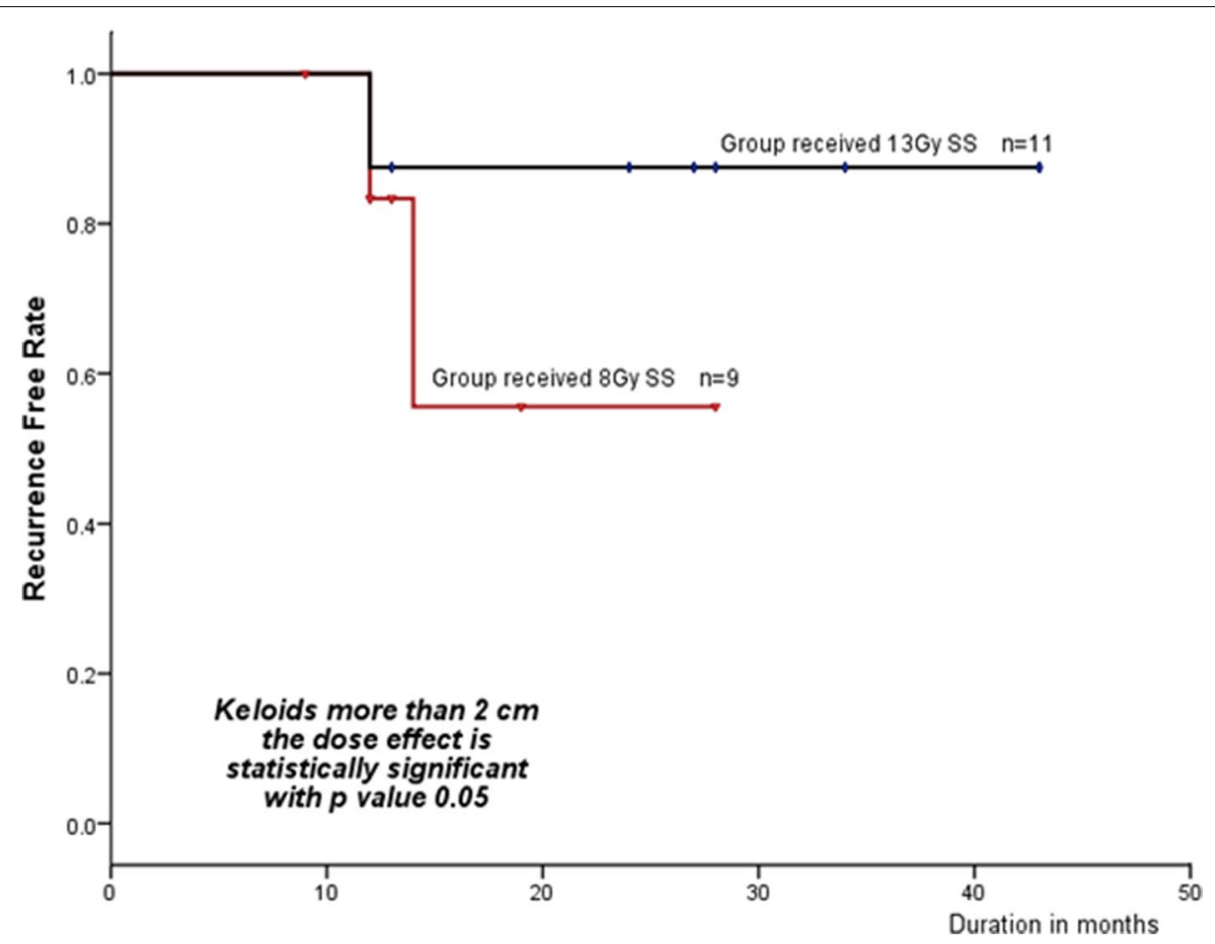

Fig. 5 The effect of increasing the dose on recurrence for keloids $>2 \mathrm{~cm}$. The curve showed significant effect of increasing dose to $13 \mathrm{~Gy} / 1 \mathrm{fx}$ compared to $8 \mathrm{~Gy} / 1 \mathrm{fx}$ on the recurrence free survival for keloid cases with size more than $2 \mathrm{~cm}$ 


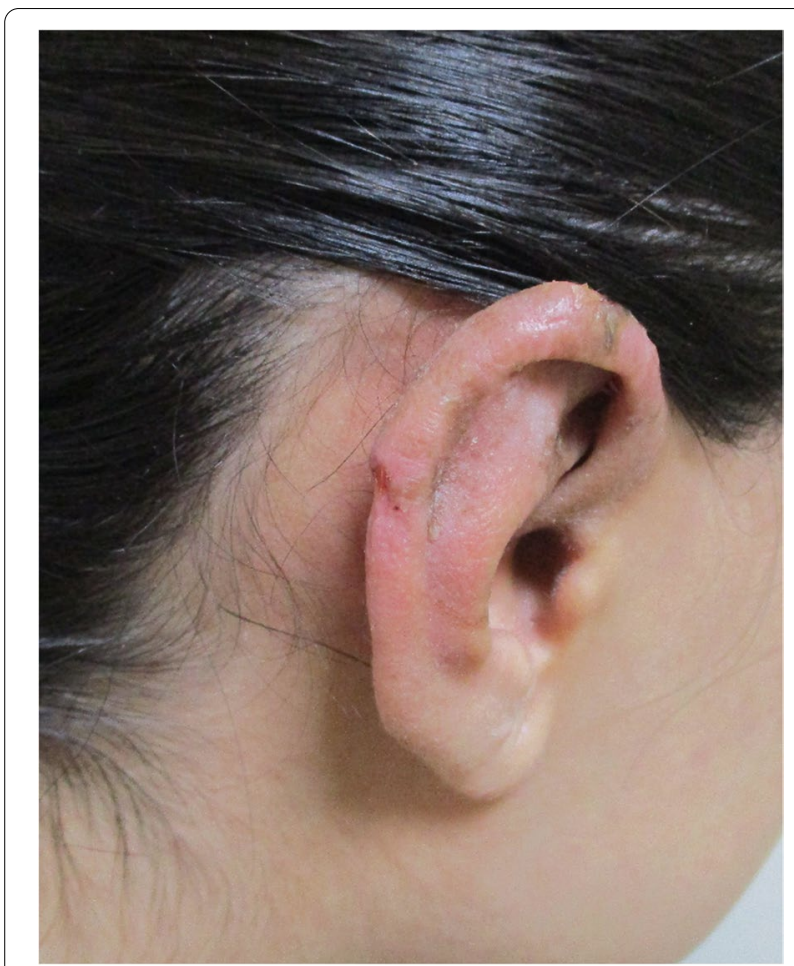

Fig. 6 Acute radiation induced side effect. Patient with G1 radiation induced acute side effect as per RTOG grading scale

\section{Discussion}

It is generally known that ear keloids do not regress spontaneously and are highly susceptible to recurrence following surgical excision. PORT is used since 1906 as an adjuvant to surgical excision and is considered a standard adjuvant approach with evidence of decreasing recurrence rate by more than $50 \%[2,25,26]$.

The weak point in most of the literature is the inclusion of a diversity of sites and even hypertrophic scars which are known to be more resistant to radiation. In our retrospective research, we studied only ear keloids to avoid the uncertainty of results and also being the commonest site affected worldwide. We aim to highlight the outcome of PORT and the effect of different prognostic factors like size and dose on the recurrence rate.

The treatment protocol at our department changed over the last 15 years. The following regimens were used; 8 Gy single shot (SS), 13 Gy SS, and many fractionated regimens as mentioned before, which make the comparison difficult however this is a common scenario in the literature $[18,20,25,26]$. It is of significant importance to check the best dose regimen for ear keloids given the known lower recurrence rate for this site specifically compared to others.

We reported $2 y$-RFR of $88 \pm 5 \%$ which is better compared to $79.4 \%$ recurrence-free published by Ragoowansi et al. who treated 35 ear lobe keloid by 10 Gy delivered by $100 \mathrm{kV}$ orthovoltage within $24 \mathrm{~h}$ of surgery [27].

On the other side, our reported recurrence is higher compared to Ilias et al. who showed a $6 \%$ recurrence rate only for his 16 studied patients [29].

Wagner et al. again showed a higher recurrence rate of $21 \%$ compared to our results [30] and Kovalic also studied 113 keloids and showed a 27\% recurrence rate. However, Kovalic's study included $53 \%$ of the cases as hypertrophic scars and none ear sites which known to be more resistant as mentioned before [31].

The insignificant difference between low dose and high dose regimens used in our study is matching that of Wagner et al. who showed that the doses of 8-10 Gy are enough and comparable to higher doses [30]. Also, Kovalic et al. treated 75 keloids by 8 Gy only and proved its effectiveness for decreasing the recurrence rate by $50 \%$ [31]. Doornbos et al. showed a recurrence rate of around $10 \%$ and the dose less than 9 Gy is enough regardless of fractionation method [32]. In a retrospective study, Rei et al. compared $8 \mathrm{~Gy} / 1 \mathrm{fx}, 15 \mathrm{~Gy} / 3 \mathrm{fx}$, and $10 \mathrm{~Gy} / 2 \mathrm{fx}$ for ear lobe keloids with insignificant difference and recurrence rate of $9 \%, 14 \%$, and $7 \%$, respectively [33]. This evidence supporting the use of low to modest radiation doses in ear lobe keloid corresponds to our results.

The size of keloid is not well-studied in the literature as a prognostic factor; however, Kovalic et al. showed that keloids greater than $2 \mathrm{~cm}$ had a higher risk of recurrence. These results support our data that showed 2y-RFR $74 \pm$ $10 \%$ for keloid cases of more than $2 \mathrm{~cm}$ size compared to $97 \pm 3 \%$ for the group of keloids less than $2 \mathrm{~cm}$ with a $p$ value of 0.02 . Interestingly, increasing the delivered dose hides this difference in our study. The $2 y$-RFR for keloids of $>2 \mathrm{~cm}$ size received $13 \mathrm{~Gy} / 1 \mathrm{fx}$ was $88 \pm 12 \% \mathrm{com}$ pared to $56 \pm 24 \%$ for the same group of keloids received $8 \mathrm{~Gy} / 1 \mathrm{fx}$ with a significant $p$ value of 0.05 .

The timing of radiation in our study was not tested as all patients started the radiation within $24 \mathrm{~h}$ following surgery as per the recommendation of many studies [1, $13,16]$.

As shown before, the orthovoltage showed marginally better 2y-RFR compared to electron beam; $92 \pm 4 \%$ compared to $72 \pm 14 \%$. These results match Yang et al's data who showed the superiority of superficial $\mathrm{x}$-ray therapy compared to electron beam therapy. They compared 14 patients who received PORT superficial intra-beam radiotherapy 8-10 Gy/2fx to 14 patients who received PORT by electron beam. There is no recurrence in the group that received superficial $\mathrm{x}$-ray compared to 5 recurrences for the group of patients who received electron beam after a median follow-up of 22.5 months [34]. Also, Jones et al. showed a low recurrence rate of around 5\% for patients who had surgical excision combined with 
platelet-rich plasma and postoperative superficial radiation therapy. But these data should be taken cautiously as the follow-up is only 3 months [35].

A meta-analysis of 72 studies by Mankaweski et al. including 9048 keloids reported the contrary. They showed no significant difference between superficial $x$-ray and electron beam with a $23 \%$ recurrence rate for both groups and a $p$ value of 0.1 [18].

Seventy-six percent of our studied cases developed G1-2 acute side effects which are higher compared to $25 \%$ reported acute reactions by Wagner et al. [30]. However, late side effects reported in our study were $14 \%$ as G1 which is comparable to Sakamoto et al who treated 194 keloids with different dose regimens. They reported 19\% late reaction in the form of hyperpigmentation, depigmentation, and telangiectasis with higher late adverse reactions up to $26 \%$ for patients who received doses of more than $20 \mathrm{~Gy} / 5 \mathrm{fx}$ [36]. Also, in support of our results, Ragoowansi et al. showed no G3 acute or late reaction [27].

We did not report any second malignancy after a median follow-up of 35 months. This is similar to most of the studies; Mankaweski [18], Sakamoto [36], and Xu [37]. Ogawa et al. concluded no association between the 5 reported malignancies and the used radiotherapy for their studied keloid cases [23]. Berman and Nestor studied 96 keloids treated by superficial $\mathrm{x}$-ray with a $10 \%$ recurrence rate and they did not report any second malignancy [38]. Also, Rishi et al. studied 40 keloids treated by electron beam and they did not report G3 side effects or second malignancies [39].

Another concept of the safety of PORT is the possibility of salvage of recurrent keloids following radiation by various treatment approaches. Assuring report by Rishi et al. supported the use of laser therapy and steroid injections for recurrent keloids following surgery and PORT [39].

\section{Conclusions}

Surgical excision followed by PORT is an effective approach for the treatment of recurrent ear keloids. Low and modest doses of radiation are effective; however, keloids $>2 \mathrm{~cm}$ need higher doses of radiation to decrease the recurrence rate. There are no reported cases of second malignancy in our study supported by a long follow-up period. Although the safety of PORT is well documented, the optimization of radiation technique and dose should be of a major concern to avoid serious side effects. There are some limitations; lack of a control group and unavailability of side effects data for some cases that may underestimate PORT complications.

We recommend a prospective larger study to optimize radiation dose as a function of keloid size.

\section{Abbreviations}

RFR: Recurrence free rate; PORT: Postoperative radiotherapy; RT: Radiotherapy; Gy: Gray; Fx: Fraction; IRB: Institutional Review Board; kVp: Kilovoltage peak; kV: Kilovolt; MeV: Mega-electron volt; RTOG: Radiation Therapy Oncology Group; SPSS: Statistical package for social science; $2 y$-RFR: 2 years recurrence free rate; EQ D2: Equivalent dose in 2-Gy fractions; BED: Biological effective dose; HVL: Half value layer; SS: Single shot.

\section{Acknowledgements}

I would like to acknowledge the radiation oncology team at King Fahad Medical City for their valuable effort supporting this study.

\section{Authors' contributions}

RM designed the study, reviewed the data, evaluated the results, edited the manuscript, and prepared the manuscript for publishing. AA reviewed statistical analysis and contributed to the drafting of the final manuscript. RA collected the data and contributed to the drafting of the final manuscript. SA contributed to the drafting of the final manuscript. SW contributed to the drafting of the final manuscript. AW evaluated the results and contributed to the drafting of the final manuscript. All authors give the consent for publication. The author(s) read and approved the final manuscript.

\section{Funding \\ None.}

\section{Availability of data and materials}

Research data are stored in our institutional repository and will be shared upon request to the corresponding author.

\section{Declarations}

\section{Ethics approval and consent to participate}

This study was approved by the ethics committee of King Fahad Medical City with Institutional Review Board (IRB) approval number (IRB/21-522). The patients provided written consent for the sake of treatment and data use for publication. I also confirm that all steps of scientific research were performed in accordance with relevant guidelines and regulations.

\section{Consent for publication}

The patients provided written consent for the sake of treatment and data use for publication.

\section{Competing interests}

The authors declare no competing interests.

\section{Author details}

${ }^{1}$ Radiation Oncology Department, National Cancer Institute, Cairo University, Cairo, Egypt. ${ }^{2}$ Radiation Oncology Department, Comprehensive Cancer Center, King Fahad Medical City, Riyadh, Saudi Arabia. ${ }^{3}$ Medical Physics Section, Radiation Oncology Department, Comprehensive Cancer Center, KFMC, Riyadh, Saudi Arabia. ${ }^{4}$ Medical Physics Section, Clinical oncology and Nuclear Medicine Department, Faculty of Medicine, Mansoura University, Mansoura, Egypt. ${ }^{5}$ Plastic Surgery Department, King Fahad Medical City, Riyadh, Saudi Arabia.

Received: 18 November 2021 Accepted: 9 January 2022

Published online: 24 January 2022

\section{References}

1. Borok TL, Bray M, Sinclair I, Plafker J, LaBirth L, Rollins C. Role of ionizing irradiation for 393 keloids. Int J Radiat Oncol Biol Phys. 1988;15:865-70. https://doi.org/10.1016/0360-3016(88)90119-8.

2. Cheraghi N, Cognetta A, Jr., Goldberg, D. Radiation therapy for the adjunctive treatment of surgically excised keloids: A review. J Clin Aesthet Dermatol. 2017;10:12-5.

3. Mari W, Alsabri SG, Tabal N, Younes S, Sherif A, Simman R. Novel insights on understanding of keloid scar: article review. J Am Coll Clin Wound Spec. 2016;7:1-7. 
4. Walliczek U, Engel S, Weiss C, Aderhold C. Clinical outcome and quality of life after a multimodal therapy approach to ear keloids. Arc Facial Plastic Surg. 2015;17:333-9.

5. Berman B, Bieley HC. Keloids. J. Am. Acad. Dermatol. 1995;33:1 17-23.

6. Renò F, Grazianetti P, Cannas M. Effects of mechanical compression on hypertrophic scars: prostaglandin E2 release. Burns. 2001;27(3):215-8. https://doi.org/10.1016/S0305-4179(00)00101-7.

7. Chan KY, Lau CL, Adeeb SM, Somasundaram S, Nasir-Zahari M, Randomized A. Placebo-controlled, double-blind, prospective clinical trial of silicone gel in prevention of hypertrophic scar development in median sternotomy wound. Plast Reconstr Surg. 2005;1 16(4):1013-20. https://doi. org/10.1097/01.prs.0000178397.05852.ce.

8. Zurada JM, Kriegel D, Davis IC. Topical treatments for hypertrophic scars. J Am Acad Dermatol. 2006;55:1024-31. https://doi.org/10.1016/j.jaad.2006. 03.021.

9. Cassuto DA, Scrimali L, Siragò P. Treatment of hypertrophic scars and keloids with an LBO laser (532 nm) and silicone gel sheeting. J Cosmet Laser Ther. 2010;12(1):32-7. https://doi.org/10.3109/14764170903453846.

10. D'Andrea F, Brongo S, Ferraro G, Baroni A. Prevention and treatment of keloids with intralesional verapamil. Dermatology. 2002;204(1):60-2. https://doi.org/10.1159/000051812.

11. Naeini FF, Najafian J, Ahmadpour K. Bleomycin tattooing as a promising therapeutic modality in large keloids and hypertrophic scars. Dermatol Surg. 2006;32(8):1023-9 discussion 1029-30.

12. Har-Shai Y, Mettanes I, Zilberstein Y, Genin O, Spector I, Pines M. Keloid histopathology after intralesional cryosurgery treatment. J Eur Acad Dermatol Venereol. 2011;25:1027-36. https://doi.org/10.1111/j.1468-3083. 2010.03911.x

13. Furtado F, Hochman B, Ferreira LM. Evaluating keloid recurrence after surgical excision with prospective longitudinal scar assessment scales. J Plast Reconstr Aesthet Surg. 2012;65(7):e175-81. https://doi.org/10.1016/j.bjps. 2012.02.005.

14. Marneros AG, Krieg T. Keloids--clinical diagnosis, pathogenesis, and treatment options. J Dtsch Dermatol Ges. 2004;2:905-13.

15. Ogawa R, Mitsuhashi K, Hyakusoku H, Miyashita T. Postoperative electronbeam irradiation therapy for keloids and hypertrophic scars: retrospective study of 147 cases followed for more than 18 months. Plast Reconstr Surg. 2003;111:547-53 discussion 554-555.

16. Ogawa R, Akita S, Akaishi S, Aramaki-Hattori N, Dohi T, Hayashi T, et al. Diagnosis and treatment of keloids and hypertrophic scars-Japan scar workshop consensus document 2018. Burns Trauma. 2019;7:39.

17. van Leeuwen MC, Stokmans SC, Bulstra AE, Meijer OW, Heymans MW, Ket $J C$, et al. Surgical excision with adjuvant irradiation for treatment of keloid scars: a systematic review. Plastic and reconstructive surgery. Glob. Open. 2015;3:e440.

18. Mankowski P, Kanevsky J, Tomlinson J, Dyachenko A, Luc M. Optimizing radiotherapy for keloids: a meta-analysis systematic review comparing recurrence rates between different radiation modalities. Ann Plast Surg. 2017;78:403-11.

19. Ollstein RN, Siegel HW, Gillooley JF, Barsa JM. Treatment of keloids by combined surgical excision and immediate post operative X-ray therapy. Ann Plast Surg. 1981;7:281-5.

20. Kal HB, Veen RE. Biologically effective doses of postoperative radiotherapy in the prevention of keloids. Dose-effect relationship. Strahlenther Onkol. 2005:181:717-23.

21. Veen RE, Kal HB. Postoperative high-dose-rate brachytherapy in the prevention of keloids. Int J Radiat Oncol Biol Phys. 2007:69:1205-8.

22. McKeown SR, Hatfield P, Prestwich RJ, Shaffer RE, Taylor RE. Radiotherapy for benign disease; assessing the risk of radiation induced cancer following exposure to intermediate dose radiation. Br J Radiol. 2015. https://doi. org/10.1259/bjr.20150405

23. Ogawa R, Yoshitatsu S, Yoshida K, Miyashita T. Is radiation therapy for keloids acceptable? The risk of radiation-induced carcinogenesis. Plast Reconstr Surg. 2009;124:1196-201.

24. Cox JD, Stetz JA, Pajak TF. Toxicity criteria of the Radiation Therapy Oncology Group (RTOG) and the European Organization for Research and Treatment of Cancer (EORTC). Int J Radiat Oncol Biol Phys. 1995;31(5):1341-6 [PubMed] [Google Scholar].

25. Yamawaki S, Naitoh M, Ishiko T, Muneuchi G, Suzuki S. Keloids can be forced into remission with surgical excision and radiation, followed by adjuvant therapy. Ann. Plast. Surg. 2011;67:402-6.
26. Recalcati S, Caccialanza M, Piccinno R. Postoperative radiotherapy of auricular keloids: A 26-year experience. J. Dermatolog.Treat. 2011:22:38-42.

27. Ragoowansi R, Cornes PG, Glees JP, Powell BW, Moss AL. Ear-lobe keloids: treatment by a protocol of surgical excision and immediate postoperative adjuvant radiotherapy. Br J Plast Surg. 2001;54(6):504-8. https://doi. org/10.1054/bjps.2001.3656.

28. Lickinger JC. A radiobiological analysis of multicenter data for postoperative keloid radiotherapy. Int J Radiat Oncol Biol Phys. 2011;79(4):1164-70.

29. Petrou IG, Jugun K, Rüegg EM, Zilli T, Modarressi A, Pittet-Cuénod B. Keloid treatment: what about adjuvant radiotherapy? Clin Cosmetic Invest Dermatol. 2019;12:295-301.

30. Wagner,W.; Alfrink, M.; Micke, O.; Schäfer, U.; Schüller, P.;Willich, N. Results of prophylactic irradiation in patients with resected keloids-a retrospective analysis. Acta Oncol. 2000, 39, 217-220.DOI: https://doi.org/10.1080/ 028418600430806

31. Kovalic JJ, Perez CA. Radiation therapy following keloidectomy: a 20-year experience. Int J Radiat Oncol Biol Phys. 1989;17:77-80.

32. Doornbos JF, Stoffel TJ, Hass AC, et al. The role of kilovoltage irradiation in the treatment of keloids. Int J Radiat Oncol Biol Phys. 1990;18:833-9.

33. Ogawa R, Tosa M, Dohi T, Akaishi S, Kuribayashi S. Surgical excision and postoperative radiotherapy for keloids. Scars Burns Heal. 5:1-11. https:// doi.org/10.1177/2059513119891113.

34. Yang X, Shao Y, Yu W, et al. A novel radiotherapy approach for keloids with intrabeam. Biomed Res Int. 2019;2019:4693528.

35. Jones ME, Hardy C, Ridgway J. Keloid management: a retrospective case review on a new approach using surgical excision, platelet-rich plasma, and in-office superficial photon $x$-ray radiation therapy. Adv Skin Wound Care. 2016;29(7):303-7.

36. Sakamoto T, Oya N, Shibuya K, Nagata Y, Hiraoka M. Dose-response relationship and dose optimization in radiotherapy of postoperative keloids. Radiother. Oncol. J. Eur. Soc. Ther. Radiol. Oncol. 2009;91:271-6.

37. Xu J, Yang E, Yu NZ, Long X. Radiation therapy in keloids treatment: history, strategy, effectiveness, and complication. Chin. Med. J. 2017;130:1715-21.

38. Berman B, Nestor M, Gold M, Raymond I, et al. A retrospective registry study evaluating the long-term efficacy and safety of superficial radiation therapy following excision of keloid scars. J Clin Aesthet Dermatol. 2020;13(10):12-6.

39. Rishi K, Sarkar N, Kesari P, Srinath BS, et al. Single institution experience of postoperative electron beam radiation therapy in the treatment of keloids. Adv Radiat Oncol. 2021;6(2):100596. https://doi.org/10.1016/j. adro.2020.10.009

\section{Publisher's Note}

Springer Nature remains neutral with regard to jurisdictional claims in published maps and institutional affiliations.

\section{Submit your manuscript to a SpringerOpen ${ }^{\circ}$ journal and benefit from:}

- Convenient online submission

- Rigorous peer review

- Open access: articles freely available online

- High visibility within the field

- Retaining the copyright to your article

Submit your next manuscript at $\boldsymbol{\nabla}$ springeropen.com 